\title{
LEITURA ETNOPSICOLÓGICA DO SEGREDO ${ }^{\star}$
}

Vinciane Despret ${ }^{\star}$

\section{RESUMO}

O texto apresenta uma discussão crítica acerca das práticas psicológicas, destacando o segredo na psicoterapia. A autora resgata a ideia do segredo como algo que separa, segrega o que é público do que é privado, o que pode e o que não pode ser mostrado, envolvendo não só questões culturais mas, sobretudo, questões políticas. A prática clínica pode ser um dispositivo que "trata o segredo pelo segredo", construindo uma noção de interioridade que fundamenta modelos imperativos de tratamento. Posteriormente, a autora desloca essa discussão para o domínio das pesquisas em ciências humanas revendo a questão da imposição do anonimato que, para ela, provoca o "efeito sem nome" e instaura uma relação de assimetria na pesquisa, provocando uma distribuição equivocada de poder.

Palavras-chave: psicologia clínica; diagnóstico; pesquisa; etnopsicologia.

\section{THE ETHNOPSYCHOLOGICAL READING OF SECRET}

\begin{abstract}
The text presents a critical discussion about psychological practices, focusing on the secret in the psychotherapy. The author rescues the idea of secret as something that separates, that sets apart what's public and what is private, what can or cannot be showed, including not only cultural subjects, but also, especially, political subjects. The clinical practice can be a device which "treats the secret by itself", building a sense of inferiority which establishes mandatory treatment models. Then, the author displaces this discussion to the domain of Human science research, checking the imposition of anonymity that, for her, causes the "unnamed effect" and establises an asymmetry relation on the research, promoting a mistaken distribution of power.
\end{abstract}

Keywords: clinical psychology; diagnoses; research; ethnopsychology.

\footnotetext{
^Tradução de Carlos Marconi. Revisado por Marianne Strumpf.

$\star \star$ Doutora em Filosofia e Letras. Departamento de Filosofia. Universidade de Liège Place du XX Aout 74000 Liège, Bélgica.

E-mail: V.Despret@ulg.ac.be
} 


\section{Primeira PARTe: O SEgRedo NA PSICOTERAPIA}

Em 1890, um homem que chamaremos Achille, se apresenta para consulta no Salpetrière. Ele foi enviado pelo médico da pequena cidade da província na qual ele vive e exerce a profissão de homem de negócios. Charcot o recebeu e o confiou rapidamente ao psiquiatra Pierre Janet. Achille apresenta todos os sintomas de possessão diabólica. Ele se encontra em um estado de agitação furiosa, profere blasfêmias, fala tanto com a voz do diabo quanto com a sua própria. Durante a primeira entrevista Janet toma conhecimento que os sintomas eclodiram subitamente seis meses antes, após o paciente ter retornado de uma curta viagem de negócios. Após haver tentado diversos enfoques, Janet conseguiu hipnotizar o doente e o fez contar a história de sua doença. Achille revela que durante esta viagem de negócios, ele havia sido infiel à sua esposa, havia em seguida tentado esquecer esse incidente, mas havia sido invadido pela culpa e pelo medo de ser condenado; é então que, de repente, foi possuído pelo demônio. A revelação desse segredo conduzirá lentamente Achille em direção à cura, pois ela permitirá a Janet superar o que ele chama as "ideias fixas subconscientes" de seu paciente.

A história, tal como ela é retomada por Henri Ellenberger (1995) em seu artigo sobre os segredos patogênicos, apresenta uma característica interessante: ela conta de fato a sucessão de duas histórias, colocando em cena dois mundos de pensamento diferentes. O primeiro desses mundos, que Ellenberger indica tratar-se de um grupo de indivíduos habitados pela superstição em uma província francesa longínqua, nos coloca em presença de seres invisíveis dotados de forças suficientes para fazer os humanos agirem, torná-los doentes de uma maneira que carrega sua assinatura. O segundo mundo será aquele no qual desemboca o percurso de Achille quando ele é recebido no hospital. Certamente, a história poderia aparecer nesse momento como o resultado daquilo que foi colocado no lugar. As coisas entretanto são um pouco mais complicadas: essa segunda história não é o simples prolongamento da primeira; ao contrário, ela vai retroativamente restabelecer aquilo que diferentemente, a reconstrói fazendo intervir outros elementos. A metamorfose não se traduz no epílogo da cura, ela advém da entrada de um jogo, ela se constitui na reconstrução da própria experiência do transtorno e modifica seus atores. Os invisíveis que tratavam Achille do exterior tornam-se com a teoria de Janet, aquilo que fará agir Achille do interior, a relação que se inscreveu como uma relação com a exterioridade, em direção a outras intencionalidades, é totalmente deslocada e convertida em uma relação completamente diferente. A desordem é agora instalada na psiché. O que, no primeiro mundo, podia se traduzir como punição torna-se, no segundo culpa e, portanto, totalmente acessível a uma teoria ou uma técnica da psiché. Achille era possuído pelo demônio em um mundo onde os exorcistas oferecem soluções aos problemas, ele vai tornar-se progressivamente, a partir de sua entrada no hospital, em um paciente sofrendo de "idéias fixas subconscientes" em perfeito acordo com as preocupações teóricas de Janet. De algum modo, Achille está somente possuído por ele mesmo. E sempre em concordância com as teorias que lhe impuseram essa metamorfose, ele se curará livrando-se daquilo que a teoria vai lhe ajudar a construir não somente como um segredo, mas como um segredo que simultaneamente tem o poder de 
torná-lo doente e de curá-lo. Em outras palavras, Janet vai propor a Achille redefinir seu problema de acordo com a maneira como ele mesmo pode intervir: o que era possessão por uma entidade estrangeira tornar-se-á "segredo". O segredo não se torna tão mal apenas porque ele oferece uma via real para a cura.

Vejamos por que esse caso me interessa, ele torna particularmente legível a maneira como a cultura não apenas propõe o cuidado, mas vai guiar, influenciar inclusive a maneira como as pessoas experienciam seus problemas. Lá onde a cultura multiplica os seres que intervêm de maneira invisível na vida das pessoas, as pessoas querem se deixar capturar por esses seres para dar um senso e um conteúdo a seu mal-estar; lá onde a psiché, os pensamentos inconscientes, a culpabilidade são considerados responsáveis pelos problemas, as pessoas vão orientar sua experiência do mal-estar como uma experiência psíquica, de problemas mentais, de efeitos de culpabilidade, de desejo etc. Eu digo a cultura no seu conjunto, cultura de demônios ou cultura de psichés, sabendo que as proposições terapêuticas são parte integrante da cultura. E portanto, as proposições terapêuticas vão participar da maneira como as pessoas vivem a experiência do sofrimento. Vimos isso com Achille. E vimos em numerosas e recentes análises: Ian Hacking (1995) em A alma reescrita se surpreende por exemplo que as personalidades múltiplas sejam tão numerosas nos Estados Unidos e quase ausentes na Europa francófona e considera o efeito conjunto das teorias, do interesse dos psis pelos traumas de infância e o êxito de certas história que relatam a vida de personalidades múltiplas. Hacking tenta resolver essa questão constituindo uma teoria de classificações, e no seio dela, a noção de gêneros interativos. O gênero, explica Hacking, é uma maneira de classificar. Para expor sumariamente, há gêneros indiferentes, como por exemplo, a classificação de coisas "indiferentes" à classificação, como as moléculas que pouco se importam a respeito do que se pense delas e que continuam sua vida de molécula. Falaremos de gêneros interativos quando a classificação afeta, em contrapartida, aqueles que são classificados como tais:

As ciências ditas humanas, ou sociais [ele diz em sua lição inaugural no Collège de France] não diferem fundamentalmente das ciências ditas da natureza sob o pretexto de que elas tratam daquilo que se denomina construções sociais. Elas tampouco não diferem porque dependem mais da compreensão [Verstehen] que da explicação, predição e controle. Elas diferem porque há uma interação dinâmica entre as classificações desenvolvidas nas ciências sociais e os indivíduos ou os comportamentos que foram classificados. Ao qualificar um tipo de pessoa ou comportamento, podemos afetar diretamente ao ponto mesmo de transformá-lo (HACKING, 1995).

Podemos assim dizer que os atuais sistemas de diagnóstico e tratamento contribuem eles mesmos para produzir um gênero de comportamento anormal característico da doença. Classificação e diagnóstico são então construídos, e esta própria construção interage com as pessoas perturbadas e contribui para produzir 
seu comportamento, o que por sua vez, confirma o diagnóstico. A interação pode certamente assumir diferentes formas: uma classificação imposta de cima pode ser reordenada diferentemente pelas pessoas classificadas: a revolução gay é um belo exemplo disso. As pessoas podem ao contrário responder ao diagnóstico conformando-se a ele: as histéricas de Charcot eram bem mais histéricas que as de seus colegas de província e o fato de que as histéricas praticamente não existam mais hoje em dia confirma o efeito da classificação: não há mais um nicho ecológico para a histeria. Da mesma forma, as personalidades múltiplas existem somente lá onde há terapeutas que estão disponíveis para operar esse tipo de diagnóstico.

Por outro lado, Philippe Pignarre (2001) se inquieta com o fato de a depressão se tornar uma epidemia no momento em que o mercado está inundado de antidepressivos: os medicamentos criaram o transtorno, os doentes são "reconhecidos" nessa nova sintomatologia e copiaram seus sintomas dos medicamentos psicotrópicos considerados capazes de agir sobre esses mesmos sintomas. Mikkel BorchJakobsen (2002) atribuirá esta mobilidade das "doenças transitórias" ao caráter de profecia autorrealizadora dos diagnósticos. Ou, para falar de maneira mais geral, como propõe o etnopsiquiatra Tobie Nathan (2001, p. 239) a propósito do autismo infantil, "a teoria dos terapeutas constrói a patologia de que eles cuidam".

Voltemos à presença de Achille. Afirmei que a leitura dessa história torna legível uma mudança que se opera na maneira como tratar os transtornos: a relação que se inscrevia como uma relação com a exterioridade, com outras intencionalidades, é totalmente deslocada e convertida em uma outra relação. A desordem é, agora, instalada na psiché. O que, no primeiro mundo, podia se traduzir como punição transforma-se, no segundo, em culpabilidade e, portanto, plenamente acessível a uma teoria, quiçá a uma técnica da psiché. Janet vai propor a Achille redefinir seu transtorno em concordância com a maneira como ele mesmo pode intervir: o que era possessão por uma entidade estrangeira torna-se "segredo". O segredo não torna tão doente apenas porque ele oferece uma via real para a cura.

Lá onde as técnicas se dirigem à psiché, se declinam sobre o modo de revelações, se estendem na ordem da verdade e, sobretudo, ambicionam buscar as causas no interior do indivíduo, a doença será definida como alguma coisa interna, ligada ao núcleo mais profundo da pessoa. $\mathrm{O}$ segredo aqui desempenha então plenamente seu papel; ele define simultaneamente o acesso e o conteúdo, ele atualiza a interioridade e lhe dá consistência. $\mathrm{O}$ invisível que faz agir não está mais alhures, ele está agora no interior das pessoas, aguardando visibilidade.

Certamente, podemos nos referir a essa prática e encontrar, agora, o sentido da análise conduzida por Ellenberger (1995) quando retoma a longa história das curas dos segredos patogênicos, na tradição cristã. Dessa forma, os rituais de confissão da religião católica, além do caráter essencialmente religioso, eram considerados como podendo algumas vezes trazer a cura de uma doença física ou mental. Antes disso, afirma Ellenberger (1995, p. 184), formas do que ele chama "Psicoterapias primitivas" consideravam a confissão de faltas cometidas como 
um procedimento mágico capaz de curar as doenças. Ele encontra isso igualmente em numerosos testemunhos nas civilizações antigas, indo dos Astecas aos povos da Mesopotâmia.

Poderemos certamente questionar a maneira como Ellenberger (1995) revisita a história quando ele traduz a ligação entre erro e desordem em outra articulação que assume o fato que a confissão de um segredo (por conseguinte patogênico), o erro, constitui em si "o" processo de cura. E poderíamos, portanto, perguntar se essa leitura não é justamente aquela herdeira dessa forma de ideologia, diagnosticada por Foucault (1976), a qual de um lado, entende a confissão como a forma mais altamente valorizada por produzir a verdade no Ocidente, e, de outro, liga em uma rede de equivalência verdade e salvação. ${ }^{2}$ Podemos, além disso, à luz dessa crítica, compreender por que o caso de Achille parece tão exemplar na análise que Ellenberger conduz: se aí se encontra, com efeito, um erro, um segredo opaco ao próprio sujeito, uma confissão que produz uma verdade até então escondida, e uma cura que assinala o abandono, pelo sujeito, das ilusões que impediam essa última (a crença na possessão).

Mas há uma outra ligação, naquilo que propõe a leitura do autor, que me parece dever reter nossa atenção: aquela entre o segredo do paciente e o segredo que liga o profissional. A cura do segredo, explica Ellenberger (1995, p. 203), se faz apenas no segredo: trata-se, dito de outra forma e de acordo com os termos próprios do autor de "tratar o segredo pelo segredo".

Consideramos geralmente que o segredo profissional se constitui como uma garantia que protege o paciente, uma condição que, embora assegurada desde o início no contrato, atua no a posteriori da revelação. Inscrita no código da deontologia, ela se traduz em termos de "não divulgação". Falando mais simplesmente, tudo acontece em uma relação que poderíamos grosseiramente qualificar de causa e efeito: porque o paciente revela coisas secretas, o terapeuta se compromete a trabalhar no segredo. É uma tradução possível desse "tratar o segredo pelo segredo". Ora uma outra leitura se demonstra igualmente pertinente, a qual ao preço de uma pequena diferença, inverte essa relação de causa e efeito: é porque o dispositivo se constrói como um dispositivo (de) segredo que o paciente é conduzido a privilegiar a produção de segredos. O segredo torna-se portanto não mais uma característica supletiva do dispositivo, não mais uma garantia que protege o paciente, mas uma técnica particular que visa a construir um processo específico.

Se aceitarmos essa tradução, a questão do segredo muda de registro: não se trata mais de saber o que é um segredo, de compreender a essência, a história ou a função, mas de explorar de maneira muito pragmática "o que faz o segredo", e o que ele faz fazer (LUTZ, 2004, p. 68). ${ }^{3}$ Não o que ele faz calar, mas o que faz falar, não mais o que ele autoriza (ou o que interdita), mas o que ele cria. Não se trata mais de considerar como um "dever" inscrito em um código (e se há dever, ele pesa no momento tanto quanto sobre o paciente), mas como um aspecto da técnica que visa transformar as pessoas segundo uma teoria. Trata-se de questio- 
nar, de maneira muito mais construtivista, o que, ativamente, o segredo provoca. O segredo provoca o segredo. Nós reencontramos a proposição de Ellenberger, apenas modificada: o segredo fabrica o segredo.

E é na análise daquilo que é fabricado que as coisas se tornam interessantes, pois ela nos traz de volta às características particulares da metamorfose que Janet propôs a Achille. Lembremos, com efeito, que o primeiro trabalho de Janet consistiu de qualquer modo em provocar um curto- circuito no recurso a outras intencionalidades, os invisíveis que tratavam Achille do exterior tornaram-se aquilo que fará Achille agir do interior. Em outros termos, o trabalho consistiu em construir a interioridade. O segredo não faz outra coisa: ele fabrica seres interiores. O segredo, como dispositivo teórico e técnico, constrói uma forma particular de experiência de desordem. Ele engaja o paciente em viver e em traduzir sua perturbação enraizando-a no mais profundo de sua intimidade.

Essa tendência será ainda mais forte quando uma boa parte de nossos modelos de doença mental articulam, de maneira cerrada, teorias de distúrbios e teorias de emoções. Com efeito, as concepções de emoções que são cultivadas em nossa tradição as designam não somente como processos que contradizem a razão, ou que lhe escapam parcialmente, mas sobretudo como processos essencialmente íntimos, cujo acesso privilegiado se constitui na introspecção como via real do conhecimento da mais pura verdade de si. Voltaremos a isso durante a terceira parte, aquela sobre as emoções, mas antecipemos um pouco. A introspecção das emoções, escreve a etnopsicóloga Catherine Lutz (2004, p. 68), é "o método por excelência para descobrir o "realmente real"”. As emoções, em certos aspectos, constituem ainda mais o verdadeiro núcleo da pessoa que nos pensamos não poder controlá-las, que elas escapam à vontade, de uma parte. De outra parte, elas são ainda mais verdadeiras e íntimas na medida em que consideramos que o espaço privado (ou doméstico) é seu lugar pleno de expansão; é o espaço dos verdadeiros sentimentos, em oposição ao espaço público, historicamente constituído como o espaço desafetado da racionalidade. ${ }^{4}$ Voltaremos a essa teoria das emoções em nosso segundo ou terceiro seminário (em função de as duas partes do presente assunto vir a constituir um ou dois encontros), quando terei então a ocasião de desenvolvê-la.

A analogia com o segredo dito patogênico pode ser igualmente conduzida quando consideramos a surpreendente concepção, legível em muitas numerosas metáforas, que nos dá simultaneamente o que pode nos tornar doentes e o que pode nos curar. Tais metáforas podem, ademais, se traduzir sob a forma de uma outra mais geral: seríamos ,em relação a nossas emoções, como "panelas de pressão". Podemos ferver de cólera, explodir de raiva; não podemos nos conter. Não é somente questão de transbordamento, de válvula de escape, de liberar a pressão etc. As emoções são forças internas, que nos trabalham desde o interior e que são vividas como perigosas em seu transbordamento sempre possível; mas elas são também potencialmente perigosas se não tomamos cuidado e as "deixamos sair", as descarregamos ou as "exprimimos" no sentido etimológico do termo. "Você 
não deve guardar a cólera"; "você deve aprender a exprimir suas emoções". É necessário desabafar, cortar o mal pela raiz, ou, quando a semântica médica se interpõe, restabelecer as experiências de purga ou de sangramento.

$\mathrm{O}$ modelo segundo o qual o acesso à vida íntima constitui a chave da cura circula sob a garantia de uma evidência de tal ordem que quando os terapeutas se dirigem a pessoas de outras culturas, e são frustrados em suas propostas de cuidado, eles se remetem geralmente à incapacidade de seus doentes, com um etnocentrismo que fascina as razões desse insucesso. Assim, o psiquiatra americano Arthur Kleinman (1981) exprime sua frustração diante do que ele chama um "discernimento introspectivo limitado" dos pacientes chineses a quem ele propôs seus serviços.

$\mathrm{Eu}$ ficava, escreve ele, frequentemente exasperado e impotente tentando ajudar os pacientes chineses a falar de suas emoções disfóricas. Os pacientes que me diziam que se sentiam deprimidos, ansiosos ou angustiados, por exemplo, não pareciam poder ir além do fato de nomear o sentimento [...] Eles não poderão elaborar sobre as características intrapsíquicas e afirmam que eles não podem pensar nesses termos. Parece lhes faltar uma terminologia fina para exprimir o que eles experimentam [...] Um aspecto importante da psicoterapia com tais pacientes é lhes ensinar uma linguagem para poder comunicar suas experiências intrapsíquicas (KLEINMAN, 1981, p. 32).

Ou, como sublinha Catherine Lutz (2004, p. 63), no modo de ver chinês, os sentimentos não são percebidos como uma origem possível do desassossego, e o "discernimento introspectivo" que valorizamos, somente traduz finalmente, segundo eles, uma preocupação excessiva consigo mesmo.

As críticas que podemos dirigir à Kleinman não devem entretanto se limitar às situações marcadas pela diferença cultural. É a pertinência de nosso próprios modelos, e sobretudo a maneira como eles legitimam, até prescrevem certas formas de hierarquização, que fomos convidados a interrogar. Assim, à questão que lhe coloca Mikkel Borch-Jakobsen (2006a, p. 95) a propósito dos "efeitos de verdade" produzidos pelas teorias, o psiquiatra Georges Fischman responde que "a relação complexa com a verdade não é de igual profundidade para todos os indivíduos, a consciência dos meandros da subjetividade apenas raramente é acessível a todos os espíritos". Não podemos reencontrar a mesma forma de hierarquização presente na obra do psiquiatra confrontado com os deficientes de simbolização que seriam, se acreditássemos, os chineses? ${ }^{5}$ E essa hierarquização não reenvia, em última instância às relações de poder entre os interventores - que se ocupa de quem e de qual status corresponde a cada uma dessas atribuições? 
Com essa crítica, é a uma outra dimensão da prática que somos reenviados, dimensão que toca tanto a questão do segredo quanto a das emoções: a dimensão política. Essa duas questões, com efeito, são indissociáveis às das relações de poder. ${ }^{6}$

A questão das emoções, mas isso seria o objeto de uma análise mais longa, é uma questão que toca à maneira como se organizam as relações em uma sociedade. $\mathrm{O}$ que me interessa aqui é que ela toca igualmente a maneira como se constroem as relações entre cuidadores e doentes. Entretanto, considerar o controle das emoções unicamente no registro da repressão nos faria faltar um aspecto importante dessa relação: aquela que é necessária entender pelo controle designa tanto, senão mais, o fato de fazer uma certa experiência das emoções, por exemplo o fato de poder falar delas, de identificá-las, de dissecá-las, de interpretá-las no registro simbólico, e sobretudo, sobretudo! de traduzi-las como eventos intrapsíquicos antes que como reações a eventos exteriores. É em torno dessas competências que se desenham as hierarquizações: lembremos dos pacientes chineses ou ainda daqueles que, entre nós, cortam mais rente o menor dos meandros da subjetividade.

A questão do segredo, por sua vez, não somente organiza as relações entre interventores e pacientes, como também as relações entre os cuidadores entre si. Voltaremos a este fato, mas agora o colocando como uma questão política, de acordo com a proposição pragmática que abriu minha análise: interrogar "o que faz" o segredo.

Poderíamos começar, para responder a essa proposição, definindo o segredo como aquilo que organiza o que se mostra e o que se esconde. $\mathrm{O}$ bom senso nos diz: qualquer coisa que somente eu sei, mas que não se tem como segredo, não o é: o segredo apenas existe para designar (mostrar) o que está oculto. Mas insistir sobre o que está escondido pode nos enganar: se há algo a guardar dos segredos da família é que todos da família, ou quase todos, os conhecem. ${ }^{7}$ Este "ou quase" nos convida a diminuir e aumentar um pouco nossa definição. A etimologia nos oferece um recurso auspicioso ao propor repensar o segredo a partir do termo do qual ele é proveniente: secretus, que é a forma no particípio passado de secernere: separar. As secreções vêm da mesma raiz e designam não, como eu pensava, o que vem do interior, mas "aquilo que se separa".

Daí “colocar na solitária" que designa a prisão, não como aquilo que se devia esconder, mas como o que deve ser descartado. Não é o que faz um segredo: organizar o que deve ser separado? Podemos, nessa etapa, retomar a análise da metamorfose de Achille e refletir sobre o que é com efeito um trabalho de separação que se opera, considerando, por exemplo, que o segredo, naquilo que eu designo como um dispositivo de criação de interioridade, efetua essa separação em relação ao exterior, mas, nesse caso preciso, também no âmago da psique, agora desdobrada, separada de maneira estanque em consciência e subconsciência. 
Ora, mais geralmente, isto não é uma característica de uma parte de nossas práticas terapêuticas? O próprio dispositivo, o quadro, o consultório, o contexto da entrevista não são dispositivos que imitam, que efetuam essa separação entre um interior e um exterior?

De uma parte, nós já havíamos evocado isso, especialmente a propósito de Kleinman, podemos observar que numerosos terapeutas encorajam, por vezes de maneira aberta, por vezes de modo implícito, seus pacientes a explicar sua angústia mais em termos psicológicos que em termos somáticos ou contextuais (BARRETT, 1998). ${ }^{8}$

A etiqueta da entrevista, o colocar o paciente à vontade, a sóbria atitude de interesse por ele, as questões levantadas, o estabelecimento de um contrato de confiança - tem por objetivo revelar os sintomas mentais profundos. Em termos clínicos, uma avaliação completa e conhecida sob o nome de "entrevista em profundidade". Ela supostamente "toca" as emoções as mais ocultas ou as mais profundas. Dizemos de um clínico que ele "descobre", "faz sair" ou permite ao paciente "desabafar" [...] Emergem, então, os pensamentos, os sentimentos ou as idéias fixas "subjacentes" que o paciente tem escondidas ou que foram "profundamente ocultadas" (BARRETT, 1998, p. 61, grifo do autor).

Barret (1998) constata por outro lado que os psiquiatras mostram um interesse particular pela informação ainda não divulgada - aquilo que, com efeito, encontramos em alguns manuais de psicoterapia: "a entrevista psicológica", escreve, por exemplo, François Duyckaert (1999, p. 107), ${ }^{9}$ se acompanha de algum alívio: aquele de dizer coisas que jamais foram ditas, ou que jamais havíamos ousado pensar.

Aqui estamos, então, no coração do segredo e das emoções ,tais como nos propusemos a analisar, em suma, no coração do trabalho de produção de intimidade. O próprio dispositivo efetua essa criação, com a certeza de garantia de confidencialidade, mas também de organização do espaço, com a intimidade de uma sala de consulta apartada dos lugares da vida comum. E tanto a etiqueta da entrevista, o interesse e a atitude do terapeuta quanto a organização espacial e temporal da consulta afetam a maneira como os pacientes serão conduzidos a modificar a experiência de seu mal estar; o conjunto do procedimento participa ativamente da constituição da própria forma do transtorno em si.

Consideramos, poderíamos dar conta da forma singular desse tipo de prática remetendo-a àquilo de que elas são o produto, à criação da psique tal como nós a conhecemos atualmente, à confissão, às práticas da confissão, ao poder pastoral.

Isso, entretanto, nos permitiria compreender a quais necessidades a forma dessas práticas continua a responder, como a intervenção de novos atores no campo da psicoterapia pôde contribuir para reforçar alguns desses aspectos e como a reorganização dessas práticas e desses atores pôde trabalhar em fa- 
vor dessas escolhas. É às questões recentes e contemporâneas que a análise de Barret nos convida a nos interessar, focalizando nossas atenção nas práticas da psiquiatria institucional.

Anunciamos inicialmente a questão maior da forma desses dispositivos: as práticas de criação de interioridade - que poderíamos chamar mais simplesmente de práticas da intimidade - considerando proteger a autonomia profissional do terapeuta. $\mathrm{O}$ que queria dizer agora é que, contrariamente ao que é geralmente aceito, o segredo protege o terapeuta.

Por autonomia profissional, é necessário entender, nesse contexto, o "controle legítimo sobre o trabalho" (BARRETT, 1998, p. 56) ${ }^{10}$ quer seja vis-à-vis do Estado quer seja nas relações cotidianas com outros profissionais envolvidos no mesmo domínio. Essas últimas décadas viram uma multiplicação do número absoluto de trabalhadores sociais, do número de grupos profissionais representados e da diferenciação interna a cada grupo. Esse aumento está ligado, explica Barrett (1998), a uma expansão mais geral das profissões dedicadas aos "cuidados com pessoas". Cada uma dessas profissões consagrou seus esforços a criar sua autonomia, e, por conseguinte, sua especificidade, diante de outras profissões.

Como garantir o "controle legítimo sobre o trabalho", e, portanto, a autonomia, em um domínio de um lado cada vez mais marcado pela concorrência entre as diversas profissões de ajuda e de cuidado - as reivindicações ao direito de cuidar não sendo mais o apanágio exclusivo dos psiquiatras - e de outro lado na qual os campos de competência se sobrepõem? O "saber técnico" não pode por si só assegurar essa legitimidade. Esse último é transmissível, público, e pode ser expresso na forma de um código racional, formulado com precisão, e portanto suscetível de ser abertamente comunicado aos estudantes e mesmo às pessoas externas à profissão. Em outros termos, a formulação de um saber especializado sob a forma de regras e de prescrições tem por consequência aquilo que define a competência de uma profissão repousa sobre um saber acessível às pessoas externas, abrindo assim a profissão a um controle externo e assim à ameaça sempre possível do dever de "prestar contas".

É lá onde os dispositivos de exploração das profundezas e das regiões íntimas vão se constituir como o principal terreno do saber do psiquiatra. E isso lhe assegura simultaneamente uma boa parte de seu poder hegemônico sobre os "casos" e sua autonomia profissional.

De um lado, esta prática de profundidade, de intimidade e do segredo que o psiquiatra reivindica como seu domínio de competência vai se definir como o território daquilo que denominamos um saber "indeterminado". O que chamamos de saber indeterminado é um saber que "não se pode aprender nos livros" em oposição ao "saber técnico". Ele é resultado da experiência, durante longos períodos de tempo: ele é adquirido apenas em uma pratica de muito fôlego. 
Por outro lado, relacionando-se com o "núcleo" da pessoa, com aquilo que é mais íntimo, e portanto em nossa tradição, com o que é mais real, o psiquiatra garante deter um conhecimento do caso que ninguém poderá contestar, e que terá sempre autoridade sobre as outras definições (aquelas dos enfermeiros psiquiatras, dos psicólogos e dos trabalhadores sociais). ${ }^{11}$ Assim, o segredo como produtor da intimidade torna-se o que permite ao psiquiatra reivindicar sua legitimidade e sua especificidade, isto é, a autonomia de sua profissão em uma organização constituída por múltiplos interventores, todos eles participantes da construção dos "casos".

O psiquiatra, por conseguinte, tem relação com aquilo que há de mais real, de mais profundo na pessoa, mas, ao mesmo tempo, aquilo com que ele se relaciona torna-se também aquilo que ele pode decidir compartilhar ou não com o resto da equipe. E isto é outro aspecto do saber fundado sobre a prática do íntimo e do segredo: é um saber privado, de qualquer modo, que protege, ele também, da obrigação de prestar contas às outras pessoas interessadas pelo caso. O segredo portanto organiza não somente o que é público e o que é privado acerca do paciente; ele organiza aquilo que separa, mas produz a mesma organização na prática do profissional. É mesmo, pelo contrário, o que ele sustenta: aquilo que constrói o espaço "separado" do profissional na organização das profissões fabrica o espaço íntimo do paciente em terapia.

O segredo organiza aquilo que se mostra e aquilo que se esconde nas relações entre os profissionais; o segredo, em outros termos, organiza o que separa os profissionais. É suficiente, para se convencer, colocar, como eu faço às vezes, a questão seguinte aos interventores de ajuda e do cuidado que trabalham no setor público: há nas equipes pluridisciplinares diferenças entre o que cada um, em função de seu papel ou de seu diploma, tem direito de não repetir a propósito daquilo que se passou em uma entrevista?

O segredo, como as áreas de estacionamento nas instituições, pode tornar visíveis as hierarquias que, no trabalho, jamais são declaradas como tais.

Podemos, agora, retomar os fios que havíamos tecido ao longo de nosso caminhar: a princípio, podemos recordar do segredo que pesa de uma certa maneira sobre o paciente. Ele induz não o silêncio, não o que ele se cala, mas que ele diz aquilo que foi calado, inclusive o que se tornou segredo pelo fato de ser pensado, experienciado e enunciado como tal, portanto, o que faz existir do segredo. Nessa perspectiva, vemos se alterar a relação entre segredo e intimidade: não é tanto a intimidade que cria o segredo; é sobretudo o segredo que fabrica a intimidade. $\mathrm{O}$ que quer dizer nesse caso a intimidade? Ao menos duas coisa: a experiência da interioridade, mas também a experiência da separação entre o que é interior, privado, e o que se torna exterior, público.

O segredo, portanto, não é tanto o que se esconde ou se desvela, mas o que se separa, o que deve ser separado e, em minha opinião, aquilo que separa. Essa última definição cria uma ligação entre a exigência do segredo que pesa sobre o pacien- 
te - o segredo cria a intimidade, fabrica a interioridade, inclusive, nunca se sabe, aprende-se a se separar (por exemplo, a não mais se desabafar, a se conter, pense em tudo o que estes termos evocam) - e aquilo que se impõem os terapeutas.

Mas, é uma última coisa que faz o segredo em nossos dispositivos, uma coisa que ele induz sem que essa indução seja colocada em questão: o segredo não separa apenas o que é público e o que é privado, ele separa as coisas das quais se pode orgulhar daquelas que envergonham. Para privilegiar essas últimas. ${ }^{12}$

E essa questão é, também, uma questão política.

\section{SEGUNDA PARTE: O EFEITO SEM NOME}

Gostaria agora de abordar um outro aspecto do segredo, e que me parece interessante para os psicólogos não clínicos. Eu gostaria de progressivamente deslocar, com essa questão, do domínio da psicoterapia para aquele das pesquisas em ciências humanas. A questão que vai amarrar essa reflexão gira em torno do que eu chamo o "efeito sem nome". Retornemos a princípio à clínica.

Um fato curioso me foi narrado por uma psicoterapeuta, quando evocamos a problemática do segredo em psicoterapia. Uma de suas amigas, psicanalista, havia decidido publicar, sob a forma de um artigo em uma revista clínica, o caso de uma de suas pacientes. Para preservar o anonimato desta, ela havia modificado algumas características desta paciente. E notadamente seu sexo: ela reconstruiu o caso como se se tratasse de um homem. Ou porque esta paciente seguisse com interesse as produções de sua terapeuta ou porque ela tivesse o hábito de ler revistas clínicas, sempre que ela retomava seu caso, ela não tinha problemas, apesar dessa transformação maior, de se reconhecer. Foi assim que, durante as sessões seguintes, nossa terapeuta teve que trabalhar com sua paciente a difícil questão que ela trazia para o atendimento: porque diabos sua terapeuta acreditava então que ela fosse um homem?

Esse tipo de história corre hoje o risco de se multiplicar ainda que sob formas sem dúvida menos humorísticas. O que os psis dizem de seus pacientes interessa cada vez mais a estes últimos. E esse interesse encontra hoje meios cada vez mais numerosos de se satisfazer: testemunha isso o fato de esta paciente não ter qualquer trabalho para encontrar os escritos de sua terapeuta. Isto evidentemente implica o risco de arrastar os terapeutas em uma escalada de artimanhas, de transformações, a fim de que seus pacientes não possam se reconhecer - inclusive de, no limite, conduzi-los a se abster de escrever, o que tornaria a transmissão e o compartilhamento de saberes um pouco complicado ou de tornar o caso tão afastado da realidade que poderia se perguntar se uma ficção não seria o caso.

A questão do anonimato, o que eu chamo "o efeito sem nome" tenta então hoje um limite surpreendentemente interessante. Pois, vemos, não se trata somente de proteger o paciente para que ele não seja reconhecido por outros, mas finalmente de proteger os segredos do terapeuta em relação a seu cliente. Na ausência de que o paciente poderia vir a tomar satisfações; na ausência de que, se a terapia é sempre um processo, e eu acompanho aqui uma observação de Thierry Mel- 
chior (2006) em "Guérir par la verité" o curto-circuito da descoberta comprometeria a cura não respeitando o timing; ou na ausência de que, ainda acompanhando desta vez Mikkel Borch-Jakobsen (2006b), o terapeuta poderia ser legitimamente suspeito de haver transgredido o pacto de ignorância que protege o paciente das perguntas de seu terapeuta.

Poderíamos, além disso, demandar se a função do anonimato não se articula àquela já sublinhada aqui, a propósito do segredo e da ética da confidencialidade no quadro das psicoterapias e mais largamente da medicina: proteger os profissionais. É, com efeito, a esta conclusão que chegam ainda que por caminhos diferentes, o antropólogo das práticas em torno da loucura, Robert Barrett (1998), em seu Traite des fous e o sociólogo da medicina, Jean Peneff, (2005) no capítulo consagrado ao segredo médico em seu France malade de ses médecins. Eu não retomarei aqui seus críticas para guardar senão o fio comum que simultaneamente liga suas análises e se articula à questão do anonimato: ${ }^{13}$ a ética da confidencialidade, a prática do segredo têm - principalmente $^{14}$ - a intenção de proteger a autonomia do profissional, de prevenir a possibilidade de críticas externas, isto é, como escreve Peneff (2005), de manter os profanos à distância respeitosa.

A princípio, não podemos ignorar, essa prática do anonimato não é exclusiva das práticas de cuidado. Nós a encontramos, por exemplo, nas investigações da psicologia e da sociologia. E o mesmo motivo pode ser oposto a todo questionamento desse uso: trata-se de proteger as pessoas que interrogamos. Garantimos de uma só vez uma certa "verdade" do discurso, uma certa autenticidade do testemunho: as pessoas poderiam talvez temer as consequências daquilo que elas poderiam dizer e, então, esconder coisas ao investigador, inclusive lhe mentir, em função dessas consequências. $\mathrm{O}$ velho sonho positivista de uma verdade não parasitada pelas condições da pesquisa e o imperativo da deontologia se reforçam aqui mutuamente, a ponto de desviar a atenção das questões que estão subentendidas ou que acompanham as escolhas das práticas. Pois o "manter à distância os profanos" que constitui uma das questões da ética da confidencialidade nas práticas de cuidado me parece igualmente em ação aqui. Mas essa necessidade não atua tanto em direção ao exterior; ela se trama, sobretudo, ao interior da relação entre o pesquisador e o pesquisado. Para dizer simplesmente: a prática do anonimato distribui os expertises e constrói, induz ou efetua a assimetria de papéis.

O que me aparece atualmente como uma evidência não é entretanto imposta de início como uma consequência lógica das análises críticas que eu dirijo aos praticantes das ciências humanas. E porque o anonimato se comprova, em circunstâncias particulares, como um verdadeiro problema que me coloca em dificuldade, que eu comecei a colocar em dúvida os imperativos que guiam geralmente as pesquisas. $\mathrm{Na}$ origem dessa história, tratava-se de conduzir uma investigação. Isso se mostrou, de início, bastante difícil. A socióloga Antoinette Chauvenet e eu devíamos avaliar os efeitos de um programa terapêutico de apoio às famílias de refugiados nos campos da região de Splint, na ex Iugoslávia. A guerra não havia terminado, e as condições de vida nos campos, nós nos demos 
conta, pareciam prolongar inexoravelmente o trabalho de destruição. E eu me perguntava frequentemente se essa pesquisa não participava também desse processo. Temo que em alguns aspectos, ao menos no início, esse tenha sido o caso.

Ainda assim, eu tentei desesperadamente encontrar uma solução para esse problema.

Comecemos aqui por um episódio, interessante na medida em que deixa particularmente visível uma parte dos pressupostos, dos reflexos profissionais inquestionáveis que estão ligados a essa prática do segredo.

Quando cheguei, com minha tradutora, na casa da família que me esperava (os terapeutas do programa haviam explicado às famílias em que consistia nosso trabalho e nós tínhamos encontros nos apartamentos que eles ocupavam), todos estavam lá: vizinhos, amigos do lugar de origem, primos, algumas vezes muito numerosos. E esperávamos antes de começar a entrevista. Às vezes durante muito tempo que todas essas pessoas se fossem. E essas pessoas ficaram. Demorei muito para compreender o mal entendido. Para mim, formada como psicóloga mas uma socióloga teria tido o mesmo reflexo - era evidente que tendo em vista o que iríamos abordar, o quadro deveria ser íntimo e confidencial. Íamos falar de infelicidade, de perdas, de tristeza, de relações; em resumo, de todas essas coisas que fazem parte dessas esferas delicadas daquilo que consideramos como a intimidade. E eu não estava, evidentemente, me colocando a questão de saber se as pessoas que iria encontrar definiam as coisas como eu fazia, o que, sem dúvida alguma, não era o caso (mas este tipo de evidencias face às dobras profissionais não tinha a chance de se impor rapidamente). Os vizinhos, amigos, família ampla não estavam lá por acaso. Se estavam lá, era justamente em razão de minha vinda. O mal-estar acabou por se instalar, e devo a sensibilidade daqueles que me acolheram haver finalmente traduzido que visivelmente era eu que necessitava de intimidade para trabalhar. O que me parece interessante atualmente, é pensar que essa tradução tão pertinente não me tivesse ocorrido naquela época. E se eu cheguei, por um momento, a mudar a maneira como eu concebia a prática, foi, por outras vias, muito empíricas. O que eu vou lhes relatar agora é um dos múltiplos acontecimentos que concorreram para essa mudança.

Estava eu um dia na velha fábrica de Omis, perto de Split, fábrica cujas instalações haviam sido requisitadas para as pessoas refugiadas. Estava diante de um senhor de 60 anos, um agricultor muçulmano originário da Bósnia - uma vila próxima de Travnick. Um senhor magnífico com uma brilhante cabeleira branca e com olhos azuis ainda mais brilhantes. Havíamos cumprido quase todas as etapas: eu havia me apresentado, garantido a ele o anonimato e havíamos abordado os temas que orientavam minha pesquisa. Eu me encontrava diante dele e anotava cuidadosamente em meu caderno suas declarações, traduzidas pela tradutora Tatiana. Ele me falava, nesse estágio da entrevista, do desaparecimento de seu irmão.

Nesse momento, ele apanhou a caneta que eu segurava para me dizer: "Veja a senhora, isso é o que fomos. A senhora pode ter essa caneta e escrever com ela. Aqueles que fazem a política escrevem conosco. Eles não pegaram os 
filhos deles para jogar e os enviaram para a guerra. Eles pegaram nossos filhos e com eles escreveram a guerra. Somos apenas um grão de poeira nessa história". Ele se calou. E eu apenas pude me calar e vi que Tatiana também estava perplexa, tão emocionada quanto eu. O que fazer com essas palavras magníficas? Quem ousaria copiar as palavras de um poeta e simplesmente anunciar: "um poeta disse"? Esse senhor me fez um ato de resistência: tomar minha caneta nada tinha de anódino; ele resistia muito polidamente, muito gentilmente, permitindo-me assim compreender, aquilo que eu the propunha, como posição de sujeito de pesquisa.

Pois ao subordinar minha investigação ao anonimato, eu escolhia implicitamente privilegiar algumas coisas, alguns regimes de discursos; coisas que deviam permanecer "cobertas", de preferência às coisas de que podíamos nos orgulhar e que teríamos vontade de assinar.

Assim, eu lhe expliquei: "Suas palavras são tão belas que não podem me pertencer. Desenvolvemos toda nossa pesquisa mantendo o anonimato daqueles que interrogamos porque pensamos que isso poderia lhes dar confiança e protegê-los, e eu me coloco agora a questão de saber se fizemos bem. Temos querido proteger aqueles que testemunham, mas penso que deveríamos tê-los deixado escolher, deixando a questão em aberto. Muitos daqueles que eu encontrei nos disseram que o sentimento de perda da dignidade era amplificado pelo fato de que nós os chamávamos todos de "vocês, os refugiados", como uma massa anônima marcada por uma identidade que eles não haviam escolhido e na qual eles não podiam se inventar. E não levamos a sério aquilo que eles nos diziam, cada vez que escrevíamos preservando o anonimato de nossos entrevistados: "um refugiado me disse". Penso que deveríamos refletir com cada um a questão do anonimato, e que temos doravante o dever de fazê-lo. Foi com o senhor que aprendi isso". Ele retomou minha caneta, observou minha página, e então nela escreveu seu nome: Jahija Smajié.

A questão do anonimato protetor, que eu não havia jamais me colocado, se verificou nesse momento como uma questão que havíamos fechado muito rapidamente. Uma questão fechada à maneira do segredo que separa: coisas de que se envergonha e coisas das quais se orgulha (e que devem permanecer no exterior); os refugiados dos profissionais (e, eu teria um nome que iria se inscrever nos relatórios, nos artigos e posteriormente em um livro (CHAUVENET; DESPRET; LEMAIRE, 1996). Essa questão me fez aprender a colocá-la, a negociá-la, e a negociar com os riscos com aqueles a quem eu interrogava. $\mathrm{O}$ risco que pensava dever evitar era apenas um dos riscos possíveis - o de divulgar -, mas ele me impedia de levar em conta outro risco, aquele com o que me confrontei naquele momento com Jahija Smajie, o risco de "separar", de isolar, de fazer falar e ao mesmo tempo de fazer silenciar, de roubar as palavras ou de retirá-las daquele que fala. $\mathrm{O}$ risco de fazer reiniciar o segredo com sua etimologia: secretus, separar, isolar.

Compreendemos agora porque eu podia ligar essa duas histórias: minha incompreensão diante do fato de que pessoas as quais eu me dirigira tivessem podido convidar seus amigos e familiares a assistir ao encontro, e o fato de que a questão do anonimato era imposta como incontornável ou inquestionável para 
a pesquisa. O efeito "sem nome" era particularmente dramático naquelas circunstâncias porque, de certa maneira, o anonimato prolongava o que poderia ser chamado um regime de insulto - "vocês, os refugiados" - um regime de insulto ainda mais violento porque o fato de ser denominado ou considerado como um refugiado era vivido pelas pessoas como extremamente desqualificante - em síntese: qualquer um indigno, ninguém, pessoa de terceira classe, qualquer um do outro lado do mundo.

Se então esse efeito é particularmente terrível nessas circunstancias, ele nos obriga, no entanto, a refletir sobre o que ele pode produzir nas situações, certamente menos dramáticas, de pesquisa.

Abrimos com aquilo que tem todas as aparências de um paradoxo: o anonimato cria a identidade. Então, o que nomeio aqui "efeito sem nome": apagando o nome é que se cria a posição de "sujeito" de uma pesquisa - eu entendo aqui "sujeito" no sentido em que a psicologia o designa, isto é, "qualquer um" definido por sua posição de profano em uma experiência. Em outros termos, é apagando o nome que se constrói a assimetria entre o profano e o expert, é apagando o nome que se constrói a postura particular daquele que deverá assumir o papel de pesquisado diante daquele que se define, no mesmo gesto, como expert. De qualquer maneira, o anonimato exerce um papel essencial no dispositivo sob a forma de uma indução que transborda amplamente aquela de um "sinta-se livre para dizer tudo o que você quiser" inclusive de um "fale sem medo" que se dá como motivo: seja livre, realmente, suas palavras não terão qualquer consequência. É necessário refletir dois segundos a respeito da maneira como as pessoas se percebem e traduzir a situação quando lhes dizemos que suas palavras não terão qualquer consequência.

Que não nos confundamos, eu não estou conduzindo uma defesa individualista ou humanista da exigência de reconhecer "os sujeitos" dessa vez no sentido de "subjetividade" (como os psis dizem "esqueceu-se o sujeito"): trata-se de uma posição pragmática e epistemológica. Questão pragmática e epistemológica portanto, eis o efeito das práticas sem nome: elas estão sempre correndo o risco de colocar as pessoas em situações em que elas têm pouca chance de serem interessantes, e pouca chance de ficarem interessadas.

Podemos além disso nos perguntar se os dispositivos não procuram exatamente, ou dizendo mais prudentemente, não se satisfazem com o fato de as pessoas não serem muito interessantes, ou não se autorizem a sê-lo.

Eu sugiro que, agora, retornemos à psicologia de laboratório. Eu proporei a vocês acompanhar a hipótese que até o momento guiou meu percurso. Para as práticas de pesquisa, eu me apoiei em um contraste: o que é que muda, em uma prática, decidir que a pessoa tenha ou não um nome? Para avaliar esse efeito, em psicologia, eu proporei partir de um contraste existente; aquele entre as práticas que são dirigidas a "sujeitos" e as que organizam suas experiências recrutando experts competentes: aqueles que têm um nome. 
Um outro contraste recorta aquele e também se calca sobre ele: nos primeiros dispositivos, a produção de efeitos de verdade se subordina à mentira; isto é a ignorância dos sujeitos. Os segundos parecem escapar desse imperativo.

Esse imperativo da ignorância foi bem analisado por numerosos autores, especialmente por Mikkel Borch-Jakobsen, quando aproxima, de maneira interessante, o "pacto de ignorância", ${ }^{15}$ que rege a psicanálise, a demanda pelo inconsciente da hipnose, e as mentiras empregadas nas práticas da psicologia experimental: trata-se em cada um desses casos de "proteger o terapeuta ou o psicólogo da acusação de contaminar seus dados, para impedir que eles apareçam como frutos de uma interação entre o sujeito e o experimentador, o paciente e o terapeuta" (BORCH-JAKOBSEN, 2006b, p. 42). Podemos, todavia, nos perguntar se outras questões não estão ao mesmo tempo sendo operadas, não como motivos explícitos, mas como propiciadores da inquestionabilidade do pacto de ignorância que rege numerosos dispositivos da psicologia experimental.

Para começar, apresentemos nosso contraste. Ele nos faz voltar às origens da psicologia experimental em 1875. No laboratório de Wundt, a prática da mentira é praticamente ausente. Eu não sei exatamente até quando é necessário estender esse período, sempre que eu reencontro as características muito similares nas experiências que foram conduzidas pelo psicólogo alemão Oskar Pfungst, em torno de 1904. Para lembrar, Pfungst é o psicólogo que tentou elucidar, por meio de dispositivos experimentais, o mistério de Hans, o cavalo que conseguia realizar operações matemáticas complicadas (DESPRET, 2004). As coisas são entretanto um pouco mais complicadas no caso de Pfungst porque, veremos, em algumas experiências os sujeitos conheciam os meandros e resultados da experiência; em outras, Pfungst os escondia cuidadosamente.

Em contrapartida, na experiência de Tamara Dembo, na Alemanha em 1930, as coisas são bem diferentes: o dispositivo é construído "apenas" sobre um engodo (DEMBO, 1976; DESPRET, 1999). Os sujeitos são recrutados para se submeter, lhes assegura Dembo, a uma prova de habilidade muito complicada. Tão complicada que é impossível de realizar: isso levará os sujeitos a ficarem encolerizados, a se enfadar, inclusive a ameaçar de bater a porta na cara da experimentadora ou de estrangulá-la. A cólera, de fato, constituirá o verdadeiro objeto da experiência. Lembremos de passagem algumas das experiências mais célebres, desde as pseudo aprendizagens por eletricidade de Milgram (1975), ${ }^{16}$ as experiências sobre influência social (um sujeito deve formular julgamentos comparando o comprimento de linhas e se encontra com pessoas que julgam de forma completamente diferente - e que são evidentemente os cúmplices do experimentador); ou ainda aquelas sobre o altruísmo entulhando as ruas de pseudo vítimas apelando por socorro a infelizes sujeitos.

Como compreender que Wundt não tenha acreditado ser necessário aderir a essa prática da mentira e da ignorância. Não se deve concluir muito rapidamente que a ansiedade metodológica seria o produto de um esforço crescente e, posteriormente, de reflexividade ou cientificismo entre os psicólogos. Não concluamos também que o problema das expectativas do experimentador teria emergido ape- 
nas ulteriormente. Pfungst, para voltar a ele, conhecia muito bem o fenômeno das expectativas do observador tanto que ele as torna justamente as responsáveis pelas pretensas competências de Clever Hans, o cavalo. Para lembrar, Hans respondia às questões aritméticas que lhe eram propostas martelando o solo com seu casco. Ora, o que Pfungst descobre - ou melhor, verifica ${ }^{17}$ - tentando elucidar as origens desse talento algo miraculoso, é que as pessoas que interrogavam o cavalo, emitiam, sem se dar conta, sinais permitindo a esse último saber quando deveria parar de bater com o casco. Pfungst vai colocar à prova a hipótese de diferentes maneiras: vai pedir aos sujeitos para interrogar o cavalo, com o intuito de observar o fenômeno da influência das expectativas; vai igualmente desempenhar ele mesmo o papel do cavalo diante dos sujeitos, e tentar adquirir os mesmos talentos de adivinhar, nos movimentos imperceptíveis daqueles que, despercebidamente, os efetuam na quantidade equivalente ao número que têm em mente. Ora essas experiências, que eu brevemente assinalei, estão às vezes sob o regime da ignorância às vezes não: os sujeitos, nesse caso, sabem o que é esperado do experimento; pede-se a eles serem vigilantes quanto à influência de suas expectativas

As razões desse contraste entre ignorância e explicitação são visíveis se se leva em conta a maneira como são organizadas as experiências, tanto por Pfungst quanto por Wundt.

Em Wundt, inicialmente, é importante lembrar o conteúdo dos experimentos, pois ele tem importância. Wundt, ao fundar a psicologia experimental, a quer calcada sobre a fisiologia. Ele necessita de leis, em decorrência da causalidade psíquica, seu método consistirá de encontrá-las, submetendo à prova, como o faz a fisiologia experimental, os "efeitos". O objeto privilegiado sobre o qual sustenta sua investigação de efeitos será herdeiro, por sua vez, da tradição filosófica: a consciência. Será estudado dessa forma o efeito de tal estimulação sobre o mecanismo psíquico, como a percepção da diferença de luminosidade ou de pesos. A consciência se exprime pelos tempos de reação, as diferenças de percepção (por exemplo da luminosidade em função de sua superfície), dão lugar a equações traduzindo por funções os fenômenos como a percepção de diferenças de pesos. ${ }^{18} \mathrm{~A}$ introspecção, todavia, permanece a via privilegiada para explorar essa consciência: ela deve completar os dados assim obtidos. A pessoa que efetuou a discriminação, que produziu as reações - em resumo, aquela que denominamos hoje o sujeito - deve na segunda fase da experiência, relatar a maneira como suas sensações, percepções, reações ou discriminações foram produzidas. ${ }^{19}$

Mas o que aparece como muito mais exótico para nós atualmente é a maneira como as experiências se organizavam. Não havia como se falar propriamente de sujeito, no sentido contemporâneo da psicologia - além disso, não se falava assim. E é aí que reside o verdadeiro desafio simultâneo às práticas da mentira e às práticas que fazem do sujeito "um qualquer": dos efeitos "sem nome".

No laboratório de Wundt, as posições de sujeito e experimentador eram totalmente intercambiáveis. Porque a pesquisa e a educação estavam intimamente ligadas nas universidades alemãs, cada estudante era ao mesmo tempo pesquisador e trabalhava em colaboração com seus colegas e seus professores. Cada um 
conduzia sua experiência e participava das conduzidas por outros. Cada pesquisador podia, portanto, adotar, em uma experiência ou outra, tanto a posição de experimentador quanto aquela que denominamos de "sujeito", papel que recebia naquela época o bonito nome de "observador". O fato que não se designe "a fonte humana de dados" pelo nome de "sujeito" não é insignificante. Chamar de "sujeito" aquele que participa de uma experiência implica muitas coisas. O termo traduz uma distribuição muito singular e muito assimétrica de expertise e de papéis. Lembro, a título de exemplo, uma passagem da experiência de Tamara Dembo (1976) (a experiência que quer colocar os sujeitos em cólera), essa resposta muito significativa da experimentadora para um sujeito, que considerando a experiência absurda, deseja abandoná-la: "você é o sujeito, você deve continuar". E essa resposta foi suficiente para recolocar as coisas em seus lugares. Mas raros são justamente os sujeitos que se autorizam a denunciar o absurdo de uma experiência: o termo "sujeito" exerce uma indução desde o início.

Retornando a Wundt, vemos, ainda mais surpreendentemente, que as posições de sujeito e de experimentador não são sequer fixadas em função do responsável por uma dada pesquisa, uma vez que ele chega a assinar o sujeito da experiência. Ele simplesmente havia delegado a outros o cuidado de conduzir a experimentação. O próprio Wundt escolhia sempre para ele mesmo o papel de sujeito, mesmo quando testava suas próprias teorias. Por que ele não assumia o lugar de experimentador?

É a partir daqui que podemos começar a compreender o verdadeiro alcance do contraste que estou tentando construir: Wundt assumia o papel de sujeito simplesmente porque esse papel exigia muito mais de sofisticação psicológica, de competência, de expertise que o demandado do papel do experimentador! A expertise, nesse tipo de dispositivo, intervém em muitos níveis, não somente na capacidade de perceber, de discriminar, de reagir, mas intervém também em um momento crucial da experiência: o da introspecção, momento durante o qual o sujeito relata metodicamente todos os eventos de consciência que acompanharam a percepção, a discriminação. $\mathrm{O}$ fato de praticar essas experiências com experts de talento constituía então a garantia de que as observações haviam sido efetuadas com o cuidado requerido, pelas pessoas que podiam assegurar a credibilidade científica. Esses experts-colegas trabalhavam junto em um regime totalmente diferente daquele que nós conhecemos - atualmente caracterizado por uma radical assimetria de expertises - : eles estavam em um regime de confiança, poderíamos dizer. Mais interessante ainda, o nome dos "sujeitos" figurava no conteúdo dos artigos, porque justamente essa menção assumia toda sua importância: um sujeito de talento era uma garantia suplementar de credibilidade do trabalho.

$\mathrm{O}$ contraste que ressaltei em Pfungst, misturando as duas práticas, pode agora se explicar. Quando se tem que falar com "um qualquer", os objetivos da experiência são ocultados; quando se fala com sujeitos de talento, seus estudantes de filosofia, trabalhando com ele, ele se autoriza a conduzir a pesquisa sem o pacto da ignorância. E se os primeiros sujeitos são nomeados apenas pela primeira letra de seu nome (Senhorita S.), os segundos, em contrapartida, são explicitamente 
designados: Chaym, Von Manteuffel, Schumann, Von Alesch e Koffka - alguns dentre eles aliás, "farão" posteriormente seu nome, testemunha assim o fato de que podemos encontrá-los em dicionários de psicologia.

A ignorância, como o anonimato, entra portanto no laboratório quando os sujeitos profanos são convidados para ele. E é na convergência dessa dupla aparição que as questões me parecem se urdir. A ignorância e o anonimato se constituem em uma relação com o profano. Essas são técnicas que refletem e atualizam a assimetria do expert e do profano.

Essas técnicas, de fato, traduzem sobretudo uma dificuldade que encontra a psicologia como campo de saber: sua expertise pode sempre ser contestada. Não podemos nos iludir, a história da psicologia é repleta de reivindicações a um saber específico liberto de saberes populares. Muitos de seus manuais comentam além disso, na introdução, a incoerência desses saberes dando como exemplo muitas citações da sabedoria popular todas em contradição umas com as outras.

Podíamos refutar que essa vontade de ruptura com os saberes não científicos marcou a história da maior parte das ciências - a química com a alquimia, a astronomia com a astrologia. A psicologia, todavia, encontra uma dificuldade suplementar quando se trata, mais amplamente de se demarcar esses saberes práticos: a relação que ela mantém com esses últimos não é a mesma que a que podemos encontrar entre a biologia e a criação de gado, a física e a navegação, a química e a cozinha. Esses são saberes práticos não teorizados: não há proximidade ameaçadora - como escreve Isabelle Stengers (NATHAN; STENGERS, 1995), o astrólogo não persegue o astrônomo. Em contrapartida, a manutenção em distância do profano se verifica ainda mais imperiosa em psicologia, pois a psicologia de senso comum é em si mesma uma teoria, ou sem dúvida um conjunto de teorias reunidas.

Essa proximidade vivida como ameaçadora, de expertises, de profissionais e de amadores, vai induzir uma resposta mais radical por parte dos psicólogos: dirigindo-se àqueles que eles interrogam de maneira a privá-los de toda possibilidade de apelar a esse repertório de teorias que lhe poderiam ser comum (redefinida em certas circunstâncias como crenças ou representações), eles garantem efetivamente a estrita separação de saberes. Um procedimento pode garantir essa "purificação" ao definir o privilégio dos expertises: aquele que consiste em criar a assimetria entre o pesquisador e aquele que será chamado, termo que marca a assimetria, o "sujeito".

E tudo no dispositivo vai exercer como uma indução a esse papel: o fato de se chamar "sujeito", o fato da ignorância - como o sujeito poderia tomar posição em relação à questão já que ele a ignora? - e a convocação fundamental da assimetria profano-expert que constitui o fato de ser sem nome. Um "qualquer um" sem expertise e que está lá apenas para fazer o que lhe é pedido, fingindo ignorar que ele o faz porque isso lhe foi pedido. O que é em suma um sujeito? É um ser fabricado e purificado por um dispositivo de psicologia, isto é, por um dispositivo de poder organizando a demarcação de saberes. 
Não se trata de denunciar, trata-se de buscar soluções concretas. Buscar os sujeitos com talento, certamente, mas sobretudo buscar pessoas lá onde elas têm talento. É assim que eu procuro. Eu experimento. E pratico a pesquisa como uma experimentação com base na criação de interesses, se posso me inscrever naquilo que Dewey propôs. Modificando algumas vezes simplesmente a questão. Assim, após mais de dez anos de meu encontro com Monsieur Smajié, exploro os dispositivos de encontro que distribuem a expertise e que criam o interesse. Minha última pesquisa junto a criadores de animais, em cooperação com a especialista desse domínio, Jocelyne Porcher experimenta novas maneiras de atuar. Em lugar de lhes pedir "vocês podem nos descrever a maneira como seus animais tomam uma parte ativa no trabalho?" que era a origem daquilo que tentava avaliar nossa pesquisa, decidimos nos dirigir a eles diferentemente, propondo-lhes: "Em sua opinião, se nós queremos colocar essa questão aos criadores, como deveremos fazer para que ela tenha uma chance de sucesso?" Aqui, o que se trata de aprender, para nós, são as boas questões. Trata-se sobretudo de nos colocarmos em uma situação de aprendizagem, redistribuindo a expertise não somente quanto ao conteúdo, mas quanto à maneira mesmo de interrogar esses conteúdos. Como poderemos esperar constituir um saber interessante se não podemos encontrar a maneira como essas questões podem - ou não - interessar aqueles a que nos dirigimos? Ou mais precisamente, não nos oferecemos melhores oportunidades se explorarmos a maneira como nossos interesses podem se construir? É aqui que encontramos o fio pragmático que segui para reconstruir essa história: que valor poderia ter um saber se ele não agrega ao mundo e aqueles que o compõem, um pouco mais de interesse? ${ }^{20}$

\section{Notas}

${ }^{1}$ Ian Hacking (1995), Traduzido para o francês com o título L'âme réecrite; para neurose póstraumatica, Mikkel Borch-Jakobsen (2002); Tobie Nathan (2001) (ver, por exemplo, a bela análise das teorias do autismo no capítulo "Les nourrissons et les ancêtres"); para a esquizofrenia, Robert Barrett (1998); ou ainda para a depressão, Philippe Pignarre (2001). E interessante notar que, sob essa intuição comum, cada um desses autores vai propor uma análise diferente do processo que participa desta construção. Borch-Jakobsen (2002) insistirá, por exemplo, no caráter de profecia autorrealizadora dos diagnósticos. Barrett (1998, p. 121), em contrapartida, disseca a maneira como as práticas institucionais construíram os "casos"; assim, "os casos de doença mental são definidos de uma maneira que reflete a organização da equipe pluridisciplinar" e quando Tobie Nathan (2001, p. 239 e 253) submete o autismo à análise comparada de teorias terapêuticas, ele mostra o interesse técnico das proposições teóricas que modificam a natureza da criança: "a teoria dos terapeutas constrói a patologia de que eles cuidam".

${ }^{2} \mathrm{O}$ Estado moderno, ele explica, integrou, sob uma forma política nova, uma velha técnica de poder que nasceu nas instituições cristãs. O Poder pastoral. Podemos, para ilustrar essa extensão, reencontrar nas práticas psicoterapêuticas contemporâneas, duas características desse poder pastoral. De um lado, ele se preocupa com a salvação, e com a salvação de indivíduos singulares durante toda sua vida. Em seguida, essa forma de poder não pode se exercer sem conhecer o que se passa na cabeça das pessoas, sem explorar sua alma, sem lhes forçar a revelar seus segredos mais íntimos. Ela implica um conhecimentos da consciência e uma aptidão para dirigila. Lembremos igualmente desse diagnóstico que não faz mais que se confirmar : "O homem, no Ocidente, tornou-se uma besta da confissão" (FOUCAULT, 1976, p. 79-80).

${ }^{3} \mathrm{O}$ que nos obriga no presente a não mais distinguir o segredo do paciente daquele do profissional, mas a considerá-los naquilo que eles produzem de efeitos (LUTZ, 2004).

${ }^{4}$ Ver a esse respeito Despret (1999). 
${ }^{5} \mathrm{E}$ que, além da questão da pertinência dos modelos propostos, coloca aquela dos riscos que operam nas categorias diagnósticas como a dos alexitímicos (por vezes denominados analfabetos do simbólico), a respeito das quais não se pode negar que hierarquizam as pessoas tanto quanto os chamados Quocientes emocionais.

${ }^{6}$ Assinalamos que a crítica foucaultiana da confissão, que eu não retomarei nesse quadro, teria podido igualmente conduzir a uma leitura tanto do segredo quanto das emoções.

${ }^{7}$ Poderíamos igualmente, na perspectiva que desenvolvo, nos interrogarmos acerca desse interesse quase fascinador dos terapeutas pelos segredos de família.

${ }^{8}$ Robert Barrett (1998) propõe a mesma análise. Aliás, é a esta que eu devo uma boa parte das linhas que seguem.

${ }^{9}$ Não esqueceremos a pertinência daquilo que Foucault (1976, p. 80) disse da confissão em La volonté de savoir: "confessamos aquilo que há de mais difícil de dizer".

${ }^{10}$ Outras definições de autonomia profissional foram propostas pela sociologia contemporânea americana, levando em conta especialmente a diferença entre ofício e profissão. Ver, por exemplo, para a psiquiatria, J. Goldstein (1997).

${ }^{11}$ Cada uma dessas profissões pode reivindicar um domínio de competência que lhe é próprio, e então um conhecimento privilegiado do caso - o paciente em sua vida cotidiana, para os enfermeiros; seu contexto familial para os trabalhadores sociais. O que está em jogo é determinar qual desses saberes é o mais "real".

12 "Os segredos são essencialmente de ordem sexual: sensações na puberdade, fantasmas de masturbação, experiências homossexuais, e, sobretudo, o incesto" (BARRETT, 1998, p. 63). Não se pode definir melhor o dispositivo como um dispositivo de separação.

${ }^{13}$ Remeto, para uma discussão mais aprofundada sobre essa crítica, à minha contribuição em $L a$ guerre des psys: "O segredo é uma dimensão política da terapia" (DESPRET, 2006). Além disso, poderiam me censurar por confundir segredo e anonimato: o episódio relatado mais acima ilustra a maneira como essa ligação pode ser construída: não há segredo senão no anonimato; apenas o anonimato, nesse quadro, "preserva" (em princípio) o segredo, uma vez que o caso é apresentado de maneira suficientemente clara para ser reconhecido pela paciente. Veremos um pouco mais adiante como esses dois termos podem ser articulados de outras maneiras.

${ }^{14}$ Cada um desses autores mostra que o segredo responde de fato a uma multiplicidade de questões, o que conduz Penneff (2005, p. 154) a falar preferencialmente de "segredos médicos": "Uma tradição incontornável - a da confidencialidade médica - [mas, que o autor vai rapidamente mostrar a facilidade com a qual ela sempre foi alegremente contornada na indiferença geral] se transforma, então, implicitamente em solução paliativa face aos novos problemas".

${ }^{15} \mathrm{Na}$ hipnose, segundo Borch-Jakobsen, o pacto de ignorância toma a forma de uma demanda inconsciente que traduz o fato de o terapeuta pedir ao paciente para ignorar a demanda. No quadro da psicologia experimental, poderemos evocar um pacto de dupla ignorância: o cientista pede ao sujeito para ignorar aquilo sobre o que trata a experiência; o sujeito, muito freqüentemente, não ignora, mas compreende implicitamente o que o cientista lhe pede para "fazer parecer" que ignora. O que leva o cientista a ignorar que seu sujeito não ignora. Como nos disseram nossos sujeitos durante uma experiência de psicologia que conduzimos com Isabelle Stengers: "Jamais acreditamos que vocês iriam acreditar que nós acreditaríamos naquilo que vocês disseram". Essa experiência foi o objeto de um curto documentário retomando os diversos momentos do procedimento, inclusive as entrevistas (DEMORCY; DESPRET; STENGERS, 1999).

${ }^{16}$ A fim de lembrar, a experiência de Milgram (1975) consistia em fazer os sujeitos acreditarem que eles deviam eletrocutar outras pessoas em uma experiência de aprendizagem. Ler a apaixonante pesquisa conduzida junto aos sujeitos da experiência, 40 anos depois, por Ian Parker (2000), descobrindo para sua grande perplexidade que muitos desses sujeitos haviam compreendido que deviam participar de uma espécie de jogos de papéis, e "pelo bem da ciência" não haviam deixado nada transparecer.

${ }^{17}$ Essa hipótese já havia sido formulada pelo psicólogo Carl Stumpf, colega de Pfungst, em uma primeira pesquisa. O fato de Stumpf ter conduzido pesquisas a respeito de hipnose, não é sem dúvida estranho a essa intuição.

${ }^{18}$ Poderíamos evidentemente considerar para dar conta do contraste, aquilo que propõe Mikkel Borch-Jakobsen (2006b): quando se trata de objetos simples como os comportamentos próximos das atividades perceptivas ou do reflexo, isto é, de atividades que escapam à vontade de sujeitos, o experimentador poderia se sentir liberto das ameaças das expectativas. A maneira como Pfungst distribui a opacidade e a visibilidade de suas experiências, da qual Wundt considera o problema, 
me parecem responder a outras questões.

${ }^{19}$ As informações a respeito da prática de Wundt são provenientes de Kurt Danziger, Constructing the Subject. Cambridge : Cambridge University Press, 1990.

${ }^{20}$ Reencontraremos aqui a influência de William James (1998) e de seu pragmatismo.

\section{REFERÊNCIAS}

BARRETT, R. La Traite des fous: la construction sociale de la schizophrénie. Paris: Les Empêcheurs de penser en rond, 1998.

BORCH-JAKOBSEN, M. B. Folie à plusieurs. Paris: Les Empêcheurs de penser en rond, 2002.

BORCH-JAKOBSEN, M. Constructivisme et psychanalyse: débat entre Mikkel Borch-Jacobsen et Georges Fischman. Paris: Le Cavalier Bleu, 2006a. Debate entre os dois autores animado por B. Granger

BORCH-JAKOBSEN, M. L'inconscient simulé. In: NATHAN, T. (Org.). La guerre des psys: manifeste pour une psychothérapie démocratique. Paris: Les Empêcheurs de penser en rond, 2006b. p. 31-64.

CHAUVENET, A.; DESPRET, V.; LEMAIRE, J. M. Clinique de la reconstruction: une expérience avec des réfugiés en ex-Yougoslavie. Paris: L'Harmattan, 1996.

DANZIGER, K. Constructing the subject. Cambridge: Cambridge University, 1990.

DEMBO, T. The dynamic of Anger. Tradução inglesa de J. De Rivera. In: DE RIVERA, J (Org.). Field theory as human science. New-York: Gardner, 1976. p. 324-422.

DEMORCY, D.; DESPRET, V.; STENGERS, I. The Valins experiment: 19661999. In: EXPOSIÇÃO LABORATORIUM, jun. 1999 Anvers. Laboratorium. Anvers: [s.n.], 1999.

DESPRET, V. Ces émotions qui nous fabriquent. Paris : les Empêcheurs de penser en rond, 1999.

DESPRET, V. Le secret est une dimension politique de la thérapie. In: NATHAN, T. (Org.). La guerre des psys: manifeste pour une psychothérapie démocratique. Paris: Les Empêcheurs de penser en rond, 2006. p. 153-178.

DESPRET, V. Hans, le cheval qui savait compter. Paris: Les Empêcheurs de penser en rond, 2004.

DESPRET, V. Ces émotions qui nous fabriquent: ethnopsychologie de l'authenticité. Paris: Les Empêcheurs de penser en rond, 1999. 
DUYCKAERT, F. Les fondements de la psychothérapie. Bruxelles: De boeck, 1999.

ELLENBERGER, H. Les Médecines de l'âme. Paris: Fayard, 1995.

FOUCAULT, M. Histoire de la sexualitté 1: la volonté de savoir. Paris: Gallimard, 1976.

GOLDSTEIN, J. Consoler et classifier: l'essor de la psychiatrie française. Paris: Les Empêcheurs de penser en rond, 1997.

HACKING, I. Rewriting the soul. New Jersey: Princeton, 1995.

JAMES, W. La signification de la vérité. Tradução Collectif DHPI. Lausanne: Antipodes, 1998.

KLEINMAN A. Patients and healers in the context of culture: an exploration of the borderland between Anthropology, Medecine and Psychiatry. Berkeley: University of California, 1981.

LUTZ, C. La dépression est-elle universelle?. Paris: Les Empêcheurs de penser en rond, 2004.

MELCHIOR, T. Guérir par la verité. In: NATHAN, T. (Org.). La guerre des psys: manifeste pour une psychothérapie démocratique. Paris: Les Empêcheurs de penser en rond, 2006. p. 65-100.

MILGRAM, S. Obedience to Authority. New York: Perennial books, 1975.

NATHAN, T.; STENGERS, I. Médecins et sorciers. Paris: Les Empêcheurs de penser en rond, 1995.

NATHAN, T. Nous ne sommes pas seuls au monde. Paris: Les Empêcheurs de penser en rond, 2001.

PARKER, I. Obedience. Granta: Shrink, Cambridge, v. 71, autumn. 2000. p. 101125.

PENEFF, J. France malade de ses médecins. Paris: Les Empêcheurs de penser en rond, 2005.

PIGNARRE, P. Comment la dépression est devenue une épidémie. Paris: La découverte, 2001.

Recebido em: setembro de 2010

Aceito em: dezembro de 2010 